\title{
Antifungal Activity of Palmatine against Strains of Candida spp. Resistant to Azoles in Planktonic Cells and Biofilm
}

\author{
Rosana de Sousa Campos ${ }^{1,2,7}$ Cecília Rocha da Silva ${ }^{1,2,7}$, João Batista de Andrade
} Neto $^{1,2}$, Letícia Serpa Sampaio ${ }^{1,2}$, Francisca Bruna Stefany Aires do Nascimento ${ }^{1,2}$, Manoel O. de Moraes ${ }^{3}$, Bruno Coêlho Cavalcanti ${ }^{3}$, Hemerson Iury Ferreira Magalhães ${ }^{4}$, Akenaton Onassis Cardoso Viana Gomes ${ }^{5}$, Marina Duarte Pinto Lobo ${ }^{6}$ and Hélio Vitoriano Nobre Júnior ${ }^{1,2 *}$

${ }^{1}$ Dept. of Clinical and Toxicological Analysis, School of Pharmacy, Laboratory of Bioprospection and Experiments in Yeast (LABEL), Federal University of Ceará, Fortaleza, CE, Brazil

${ }^{2}$ Department of Pathology and Legal Medicine, School of Medicine, Federal University of Ceará, Fortaleza, CE, Brazil

${ }^{3}$ Department of Physiology and Pharmacology, Neuropharmacology Laboratory, Federal University of Ceará, Fortaleza, CE, Brazil

${ }^{4}$ School of Pharmacy, Federal University of Paraíba, João Pessoa, PB, Brazil

${ }^{5}$ Department Organic and Inorganic Chemistry, Federal University of Ceará,

Fortaleza, CE, Brazil

${ }^{6}$ School of Pharmacy, University of Fortaleza (UNIFOR), CE, Brazil

${ }^{7}$ Christus University Center (UNICHRISTUS), Fortaleza, CE, Brazil

*Corresponding author

\begin{tabular}{|l|}
\hline Ke y w o r d s \\
Candida spp., \\
Palmatine, Biofilm, \\
Flow cytometry, \\
Comet assay
\end{tabular}

\section{A B S T R A C T}

The incidence of fungal infections has increased and it is necessary to seek new antifungals that also act against resistant strains. Palmatine is a protoberberine alkaloid noteworthy for its various pharmacological properties, including antifungal properties. The objective of this study was to evaluate the activity of palmatine against Candida spp. strains resistant to azole in planktonic cells and biofilm, and to elucidate the possible mechanism of cell death. Palmatine showed an antifungal activity with MICs ranging from 32 to $128 \mu \mathrm{g} / \mathrm{mL}$. In the formed biofilms, palmatine reduced by $50 \%$ cell viability at the concentration of 20x MIC (C. albicans) and 10x MIC (C. tropicalis and C. parapsilosis). In the formed biofilms, the same percentage of inhibition was achieved at a concentration of 1x MIC (C. albicans) and 2x MIC (C. tropicalis and C. parapsilosis). It was found that palmatine causes damage to DNA, promotes mitochondrial depolarization and increasing the externalization of phosphatidylserine, suggesting cell death by apoptosis. The antifungal action of palmatine in Candida spp. resistant to azoles in planktonic cells and biofilm formed and in formation, as well as the fact of not having presented cytotoxicity in mammalian cells, point to a promising new anti-candida molecule. 


\section{Introduction}

Species of the genus Candida occupy the fourth place among the most common microorganisms isolated in hospital sepsis (Kumar et al., 2015). Fungal infections may progress rapidly, leading to an increase in mortality rates and hospital costs due to an increased hospitalization time (Kazak et al., 2014). The incidence of these infections has been increasing over the years due to the increasing number of immunocompromised patients, increased invasive medical procedures and the use of broad spectrum antibiotics (Yapar et al., 2014).

It is estimated that in $65-80 \%$ of infections, microorganisms are organized in the form of biofilms (Valentin et al., 2012; Bonhomme and d'Enfert, 2013). Biofilms are communities of microorganisms organized within an extracellular matrix allowing them to live in harsh environments, as well as escaping the host's immune defense system, representing a major virulence factor ( $\mathrm{Yu}$ et al., 2012). Candida spp. species have the ability to form biofilms both in the host tissue and in medical devices (Zavrel and White, 2015; Tabbene et al., 2016).

Due to the increase in fungal infections, low number of available antifungal drugs and increased antifungal resistance, it is necessary to seek new therapeutic strategies (Guo et al., 2008). In this context, palmatine is a protoberberine alkaloid noteworthy for its various biochemical and pharmacological properties, including antifungal properties $(\mathrm{Mi}$ et al., 2015; Dumont and Monari, 2015). Radix berberidis, Coptidis rhizoma and Cortex phellodendri are commonly used as Chinese traditional medicines containing isoquinolínico alkaloids, and they have been applied for more than 2,000 years because of the antimicrobial effects (QI et al., 2013). A previous study conducted by our research group demonstrated an interesting activity of berberine against strains of Candida spp. and Cryptococcus neoformans (Da Silva et al., 2016). The aim of the present study was to evaluate the antifungal activity of palmatine against different azole-resistant Candida strains in planktonic cells and biofilm. The mechanisms of action were assessed by flow cytometry and comet assay (standard single cell gel electrophoresis).

\section{Materials and Methods}

\section{Yeast strains}

Twenty strains of azoles-resistant Candida spp. (6 C. albicans, 7 C. tropicalis, $6 C$. parapsilosis, 1 C. glabrata) were used. These strains are from the yeast collection of the Laboratory of Bioprospection and Experiments in Yeast (LABEL/FF/UFC). The strains were incubated on Sabouraud dextrose agar (Himedia, Mumbai, India) at $37^{\circ} \mathrm{C}$ for 24 $\mathrm{h}$, and were then cultivated on CHROMagar Candida ${ }^{\circledR}$ medium (Himedia) to assess their purity.

\section{Cultivation and L929 cell proliferation inhibition using the MTT Test}

The procedure was performed according to Da Silva et al., (2016).

\section{In vitro antifungal activity}

The broth microdilution (BMD) antifungal susceptibility test was performed according to the document M27-S4 (Clinical and Laboratory Standards Institute, 2012) (CLSI) (CLSI, 2012) using RPMI-1640 broth (pH 7.0) buffered with $0.165 \mathrm{M}$ MOPS [3-(Nmorpholino) propanesulfonic acid] (Sigma Chemical Co. St Louis, MO, USA). Palmatine (Sigma Chemical) was dissolved in dimethyl sulfoxide (DMSO; Sigma Chemical) and tested at concentrations ranging from 0.5 to 
$256 \mu \mathrm{g} / \mathrm{mL}$. The yeasts and compound were incubated in 96-well culture plates at $35{ }^{\circ} \mathrm{C}$ for $24 \mathrm{~h}$ and the results were examined visually, as recommended by CLSI. The minimum inhibitory concentration (MIC) of compound was determined as the concentration that inhibited $50 \%$ of fungal growth. The strains $C$. parapsilosis ATCC 22019 and C. krusei ATCC 6258 were used as controls (CLSI, 2012).

\section{Yeasts suspensions preparation}

Cell suspensions were prepared from cultures in the exponential growth phase. The cells were harvested by centrifugation (1600 $g$ for $10 \mathrm{~min}$ at $4{ }^{\circ} \mathrm{C}$ ), washed twice with $0.85 \%$ saline solution (1200 $g$ for $5 \mathrm{~min}$ at $4{ }^{\circ} \mathrm{C}$ ) and then resuspended $\left(\sim 10^{6}\right.$ cells/mL) in HEPES buffer ( $\mathrm{pH}$ 7.2) supplemented with $2 \%$ glucose. Ampho B was used as a cell death control (Da Silva et al., 2014).

\section{Mechanism of action studies}

To determine their cell density, mitochondrial transmembrane potential, reactive oxygen species, annexin $\mathrm{V}$ staining and DNA damage (presence and absence of enzyme FPG), $C$. albicans azoles-resistant strain was exposed to various concentrations (MIC, 2x MIC and 4x MIC; see Table 1) of palmatine. Treatment with amphotericin B (Ampho B; $4 \mu \mathrm{g} / \mathrm{mL}$ ) (Sigma Chemical) was used as a positive control for cell death. All of the experiments were performed in triplicate in three independent experiments to according previous studies already published by our research group (Da Silva et al., 2014; Da Silva et al., 2016).

\section{Biofilm viability}

The procedure was performed according to Da Silva et al., (2016).

\section{Inhibition of biofilm formation}

The inhibition of biofilm formation followed the methodology described above with small modifications. For this test, one strain of each Candida species (see Table 1) incubated in yeast extract-peptone-dextrose at $35^{\circ} \mathrm{C}$ for 20 to $24 \mathrm{~h}$ was used. The palmatine ( 8 to 1280 $\mu \mathrm{g} / \mathrm{mL}$ ) was added at the time inoculation. After $24 \mathrm{~h}$ the test product was discarded, and the wells were washed twice with PBS. Measurement of the metabolic activity of the biofilm cells was evaluated using the 3-(4,5dimethyl-2-thiazolyl)-2,5-diphenyl-2H-

tetrazolium bromide (MTT; $1 \mathrm{mg} / \mathrm{ml}$ ) colorimetric assay. Reading of the results was conducted in a microplate reader at $540 \mathrm{~nm}$ (Pires et al., 2013).

\section{Statistical analysis}

In vitro susceptibility experiments were repeated at least three times on different days and geometric means were used to compare the MIC values. The data obtained from the flow cytometry and alkaline comet assays were compared using a one-way analysis of variance (ANOVA) followed by the Newman-Keuls test $(\mathrm{p}<0.05)$. Mean absorbance values from the biofilm formation assay were compared using one-way ANOVA followed by the Tukey test $(\mathrm{p}<0,05)$.

\section{Results and Discussion}

\section{Citotoxic activity in murine fibroblasts}

After $72 \mathrm{~h}$ exposure to palmatine no showed cytotoxicity against murine fibroblasts (L929 strain), because didn't interfered with the proliferation of cells as well as untreated control cells ( $\mathrm{p}<0.05)$. The median inhibitory concentration (IC50), lower concentration of an agent which inhibits $50 \%$ of cell growth study was higher than the range tested, $100 \mu \mathrm{g}$ / $\mathrm{mL}$. 
Antifungal effects of palmatine against azoles-resistant Candida spp. strains

Palmatine were able to inhibit the growth of all azoles-resistant strains used in the present work (Table 1). The MIC values ranged from $32-128 \mu \mathrm{g} / \mathrm{mL}$. Based on these findings, experiments were devised aiming to elucidate the mechanisms involved in the antifungal action of the palmatine against $C$. albicans (Table 1).

Loss of cell viability in azoles-resistant Candida spp. after treatment with palmatine

As shown in Figure 1, when the azolesresistant cells were treated with palmatine for $3,6,12$ and $24 \mathrm{~h}$ they exhibited significant decreases in cell viability $(\mathrm{P}<0.05)$.

Increased intracellular levels of ROS in azoles-resistant Candida spp. after exposure to palmatine

As shown in Figure 2, cells of C. albicans resistant to azoles when treated with palmatine showed no significant differences in the levels of intracellular ROS compared with the negative control.

Yeast $\Delta \psi m$ changes are induced by palmatine

Significant $(p<0.05)$ changes in the mitochondrial transmembrane potential were observed when the yeast cells were exposed to increasing concentrations of the palmatine in comparison to untreated cells (Figure 3).

\section{Externalization of phosphatidylserine in yeast cells}

In Figure 4, Candida albicans treated with palmatine showed significant increases $(\mathrm{P}<0.05)$ in the percentage of apoptotic cells when compared to the control group.

\section{DNA damage}

As shown in Figure 5, palmatine induced a significant increases $(\mathrm{P}<0.05)$ in DNA damage in the azoles-resistant Candida spp. in comparison to untreated cells. Therefore, the azoles-resistant strains that had been incubated with FPG no showed a difference significant in the damage index values after the treatment with palmatine in comparison to the control group $(\mathrm{P}<0.05)$.

\section{Effect of palmatine on the formed biofilm}

As shown in Figure 6, C. albicans in the concentration of $20 \mathrm{x}$ MIC $(1280 \mu \mathrm{g} / \mathrm{mL})$ caused a reduction close to $50 \%$ cell viability of the biofilm growth compared to the control. However, C. tropicalis demonstrated the same reduction with 10x MIC $(640 \mu \mathrm{g} /$ $\mathrm{mL}$ ) and C. parapsilosis with 10x MIC (320 $\mu \mathrm{g} / \mathrm{mL})$.

In relation to inhibition of biofilm formation, as shown in Figure 7, C. albicans in the concentration of MIC $(64 \mu \mathrm{g} / \mathrm{mL})$ caused a reduction close to $50 \%$ cell viability of the biofilm compared to the control. However, $C$. tropicalis demonstrated the same reduction with 2x MIC $(128 \mu \mathrm{g} / \mathrm{mL})$ and $C$. parapsilosis with $2 \mathrm{x}$ MIC $(64 \mu \mathrm{g} / \mathrm{mL})$.

The results of this work show that palmatine has an activity in different Candida species, such as $C$. albicans, $C$. tropicalis, $C$. parapsilosis and $C$. glabrata. The MICs found ranged from 32 to $128 \mu \mathrm{g} / \mathrm{mL}$. The lowest MIC value was for $C$. parapsilosis strains. Our results are in agreement with the work conducted by (Park et al., 1999) with sensitive clinical strains, which identified a higher antifungal activity of palmatine against C. parapsilosis strains, showing a MIC lower than $16 \mu \mathrm{g} / \mathrm{mL}$. In C. albicans, C. glabrata, C. guilliermondii and C. krusei strains, MICs were higher than $500 \mu \mathrm{g} / \mathrm{mL}$. The emergence of drugs that affect strains resistant to azoles is extremely important since these drugs are 
chosen by most Brazilian hospitals (Storti et al., 2012). After the antifungal action of palmatine against Candida spp. strains was proven, a cytotoxicity assay was performed in L929 cells. Palmatine showed no cytotoxicity regarding the cells under study, including at the highest concentration used, i.e., 100 $\mu \mathrm{g} / \mathrm{mL}$. The absence of cytotoxic activity in mammalian cells reinforces the importance of studying palmatine as a potential antifungal agent.

Upon assessing cell density, it was observed that $C$. albicans cells, when exposed to palmatine at the concentration $4 \mathrm{x}$ MIC, showed a significant decrease in cell density $(p<0.05)$. According to Figure 1, it can be observed that palmatine at the MIC concentration appears to demonstrate a cytostatic action, since the number of viable cells did not have significant increases during the study period. Da Silva et al., (2016) also found a decrease in the number of viable cells when strains of Candida spp. and Cryptococcus neoformans were treated with berberine at the concentration $4 \mathrm{x}$ MIC. This decrease was also greater than the death in the control.

Mitochondria are essential for the survival of eukaryotic cells and, at the same time, these organelles have the necessary structures for cell suicide, meaning that they are capable of controlling cell death (Galluzzi et al., 2010). In this work, the mitochondrial function in Candida albicans cells was affected after exposure to palmatine. Changes to the mitochondrial membrane potential $(\Delta \psi \mathrm{m})$ may be caused by the opening of pores. Such pores allow releasing protons and proapoptotic factors into the cytosol, such as cytochrome c (Hwang et al., 2014; Hwang et al., 2012; Da Silva et al., 2014). This mitochondrial membrane permeability is an irreversible point in the cascade of events leading to cell death by the intrinsic apoptosis pathway (Galluzzi et al., 2010).
The mitochondrial depolarization process was assessed using the fluorescent nucleophilic marker rhodamine 123. It is sequestered inside mitochondria when the membrane potential is unchanged. Thus, viable cells present a higher fluorescence due to a greater quantity of rhodamine 123 bonded to its internal positive charges. Depolarized mitochondria, however, have a lower affinity to staining, emitting a lower fluorescence (Da Silva et al., 2014). C. albicans cells treated with palmatine showed high rates of depolarized cells at the three tested concentrations (MIC, 2x MIC and 4x MIC), evidencing that palmatine damages the mitochondrial membrane.

Mitochondrial dysfunction and the increase in intracellular production of reactive oxygen species (ROS) play an important role in inducing apoptosis. ROS such as peroxide oxygen, superoxide radicals and hydroxyl radicals, when accumulated excessively in the cell, cause molecular damage leading to cell death. The imbalance between excessive ROS rate and low intracellular antioxidant defenses leads to oxidative stress, which is the major cause of apoptosis (Choi and Lee, 2015; Hwang et al., 2012).

Palmatine, at the tested concentrations, did not affect the production of reactive oxygen species (ROS) in relation to the control. It can also be noted that at the concentrations MIC, 2x MIC and 4x MIC, at a 12-24 $\mathrm{h}$ period, there was a significant decrease in ROS in relation to the control, probably due to the antioxidant action of palmatine.

A study conducted by (Pustovidko et al., 2013) demonstrated that palmatine and berberine can accumulate in isolated mitochondria or in mitochondria of live cells, and effectively protect them from oxidative damage. Ali and Dixit (2013) conducted a study in which palmatine was used to treat skin cancer in mice. These researchers found 
that palmatine promoted a decrease in lipid peroxidation levels, increasing the levels of enzymes involved in the antioxidant process

Fig.1 Density cell after treatment with palmatine

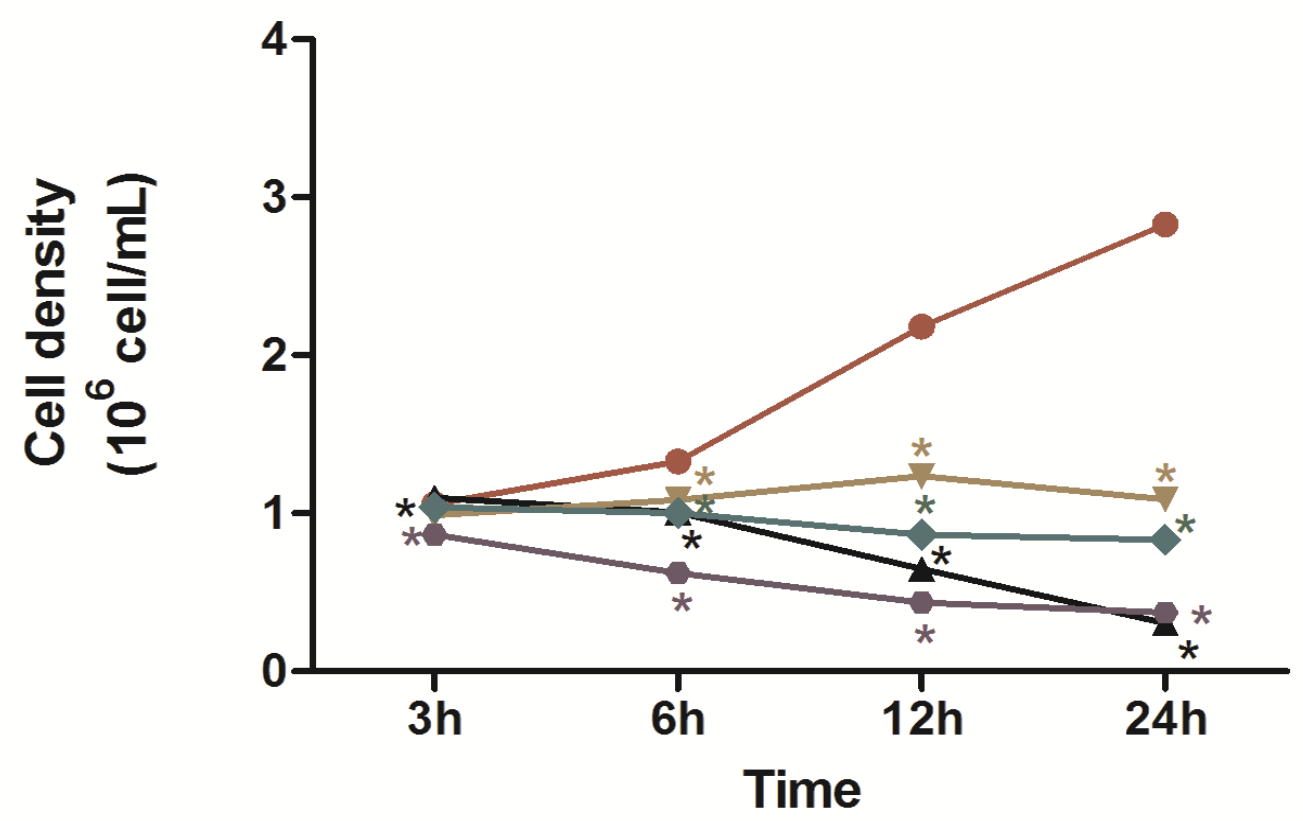

Fig.2 ROS formation after treatment with palmatine

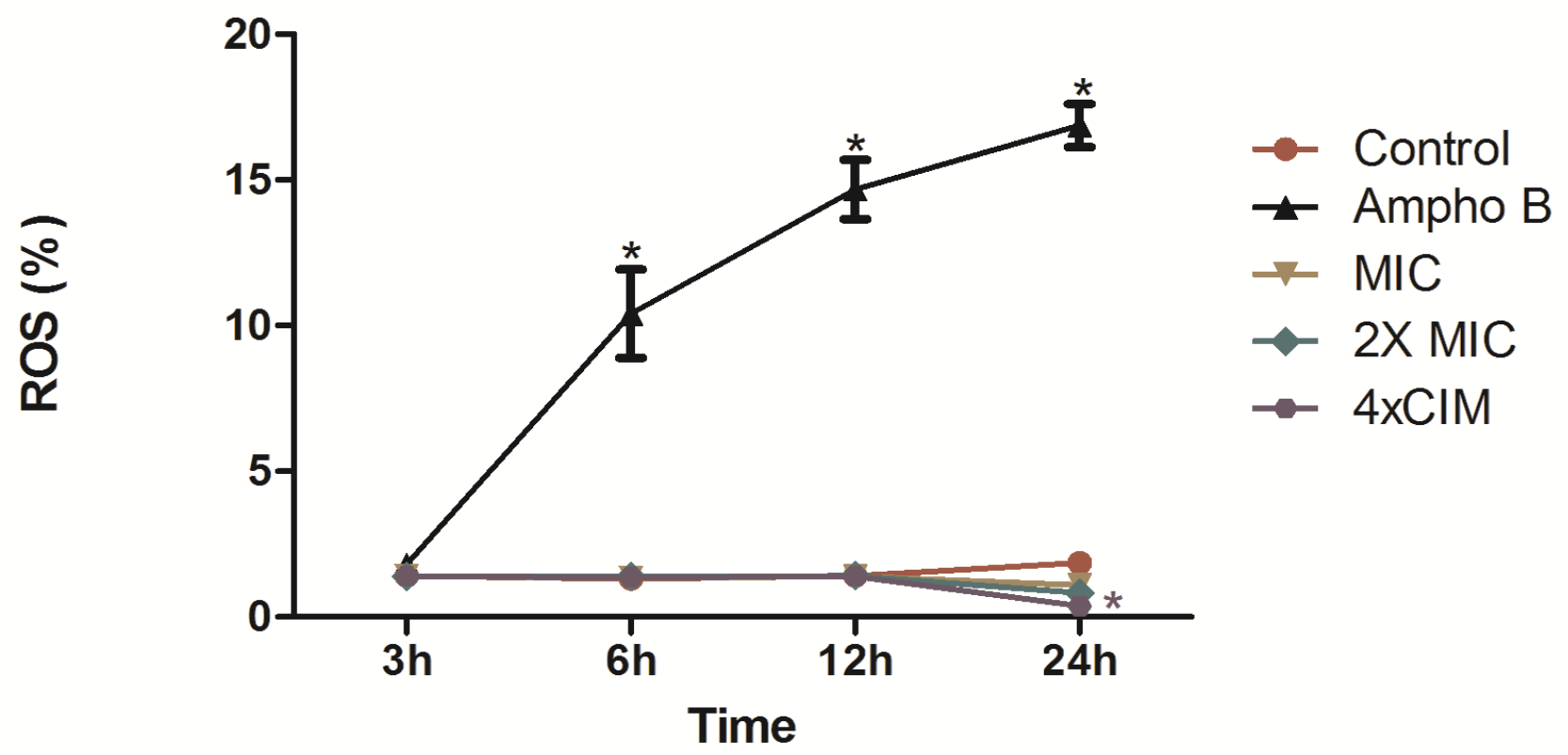
glutathione (Ali and Dixit, 2013).

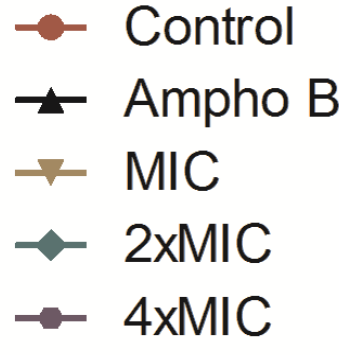


Fig.3 Effect of palmatine on the mitochondrial transmembrane potential
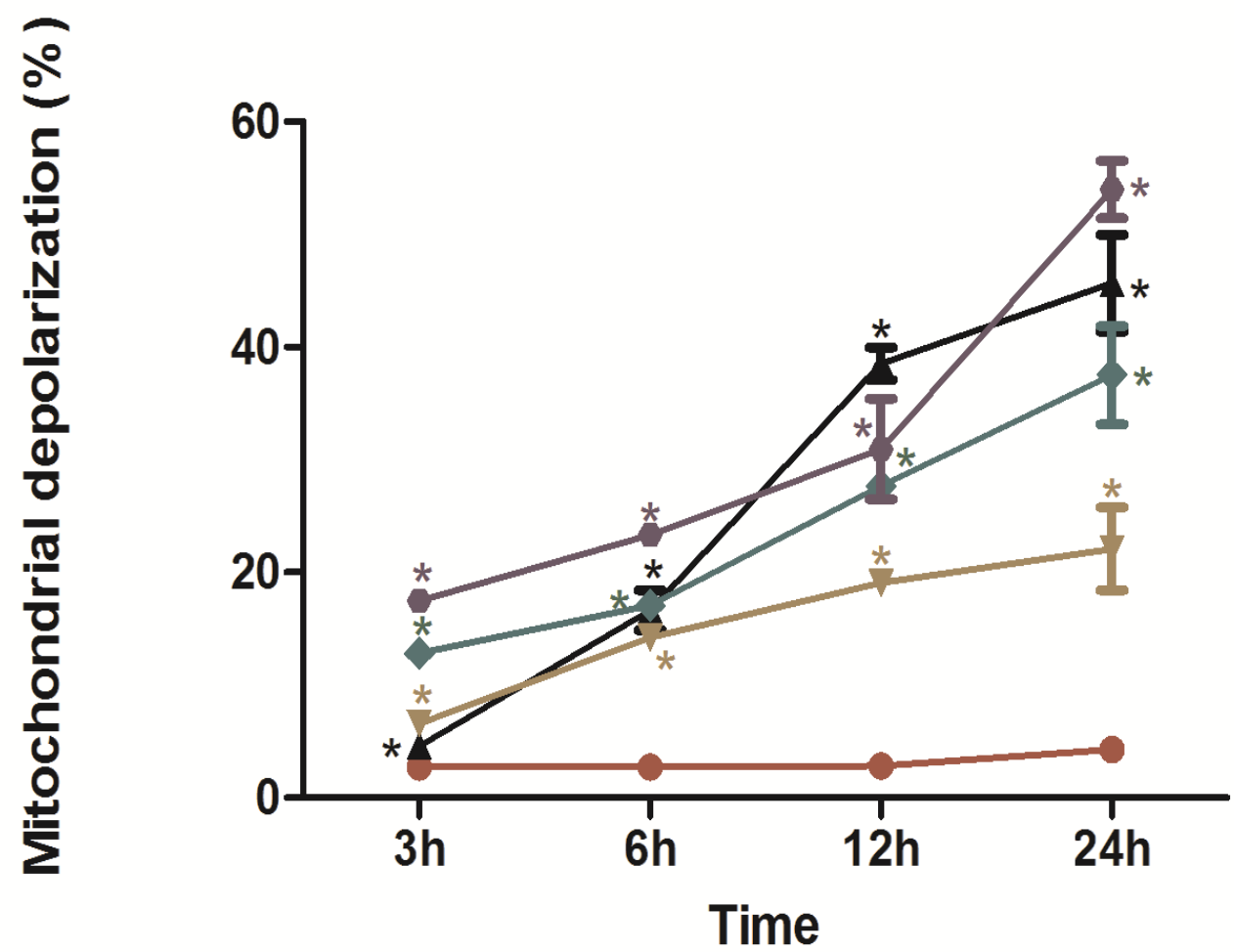

$\rightarrow$ Control

$\rightarrow$ Ampho B

$\rightarrow \mathrm{MIC}$

$\neg 2 \mathrm{XMIC}$

$\rightarrow 4 \mathrm{XCIM}$

Fig.4 Effect of palmatine on phosphatidylserine externalization
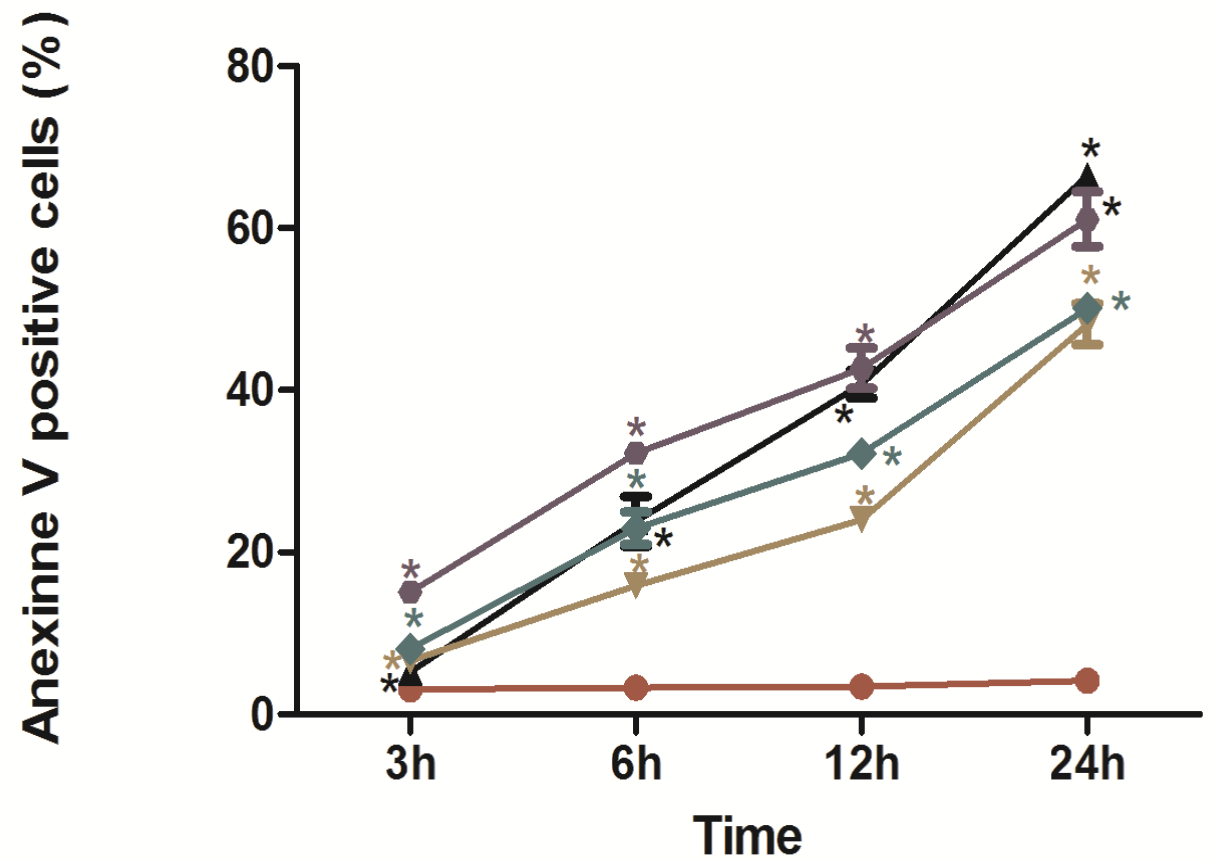

$\rightarrow$ Control

$\rightarrow$ Ampho B

$\rightarrow \mathrm{MIC}$

$\neg 2 \mathrm{XMIC}$

$\rightarrow 4 \mathrm{xCIM}$ 
Fig.5 Effect of palmatine on the DNA damage index and on the distribution of oxidative DNA damage

\section{Candida albicans}

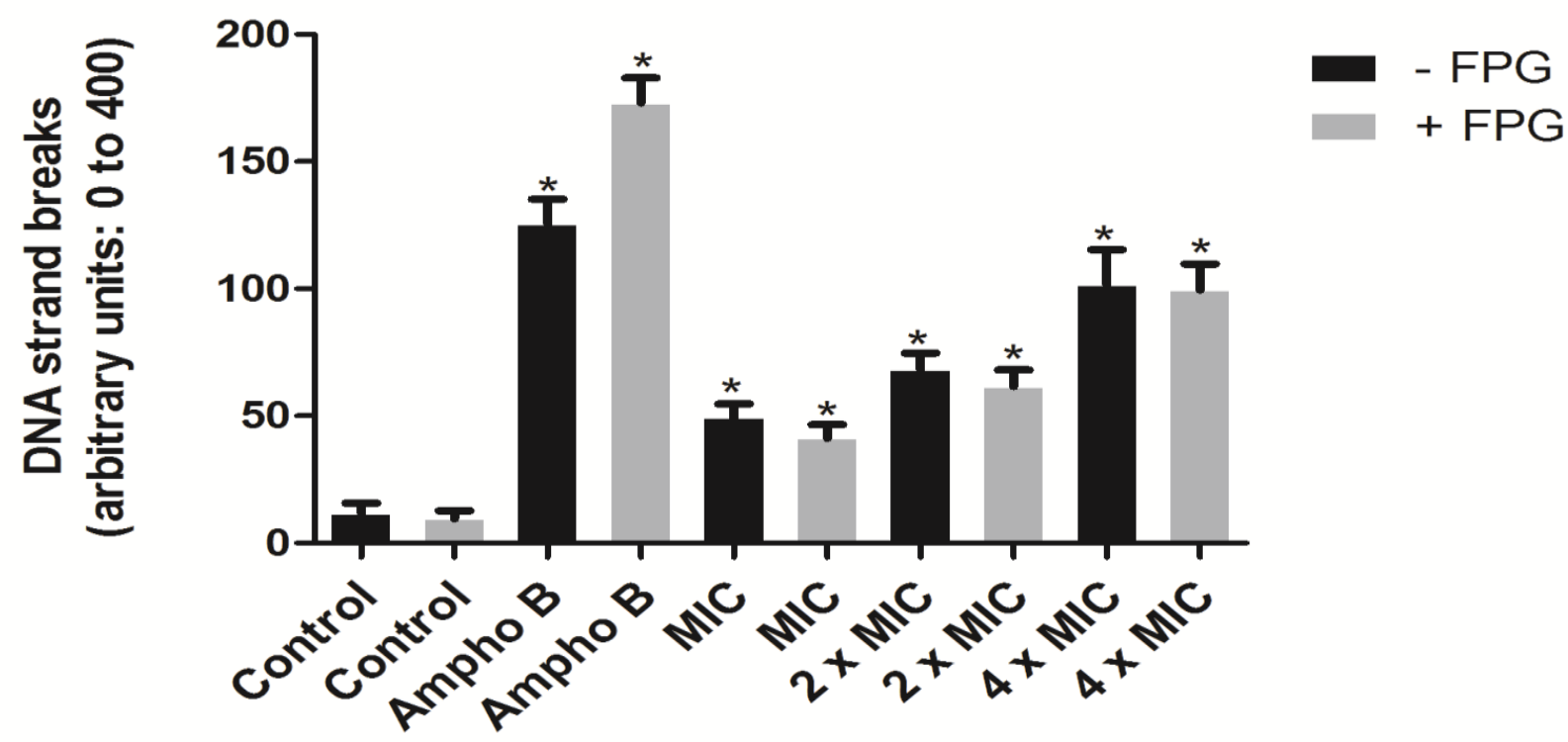

Fig.6 Effect of palmatine on the metabolic activity of biofilms formed
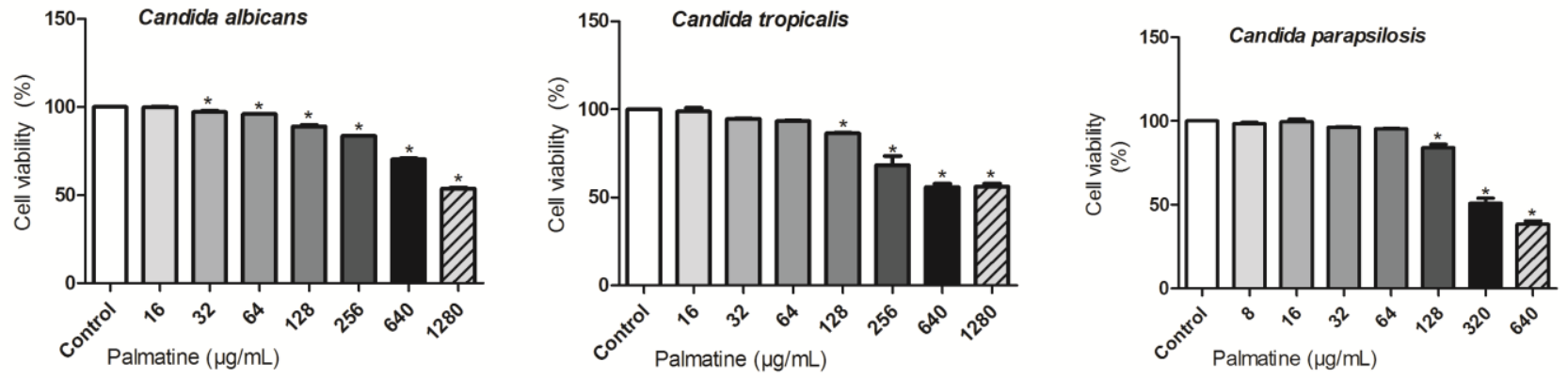

Fig.7 Effect of palmatine on inhibition of biofilm formation
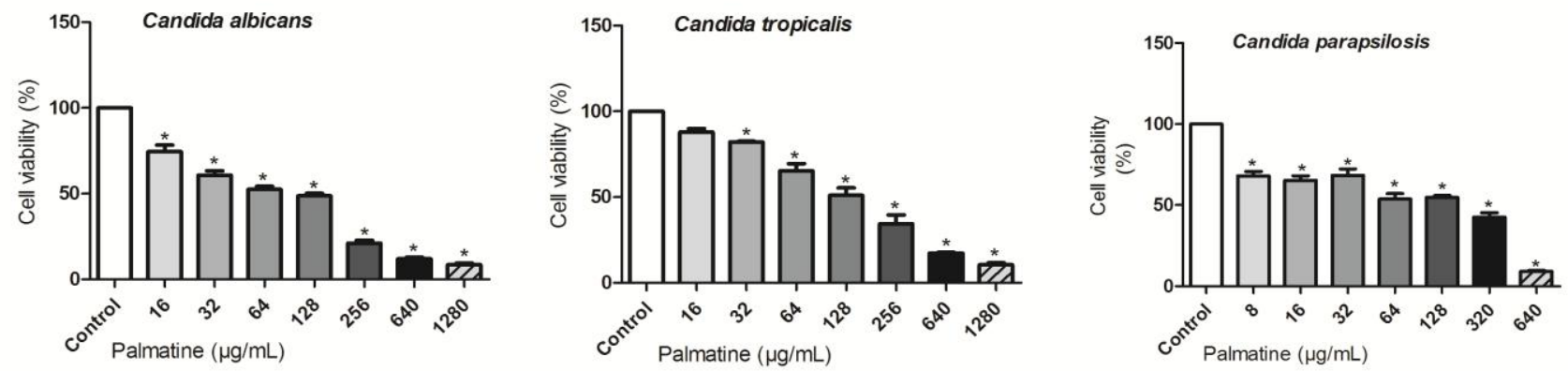
Table.1 Effect of palmatine against azole-resistant strains of Candida spp.

\begin{tabular}{|c|c|c|c|c|}
\hline & & & MIC & \\
\hline \multirow[t]{2}{*}{ Strain $^{a}$} & & & $\begin{array}{l}\text { Values of MIC } \\
(\mu \mathrm{g} / \mathrm{mL})\end{array}$ & \\
\hline & Origin & No Genbank & $\begin{array}{l}\text { Resistance } \\
\text { Phenotype }\end{array}$ & Palmatine \\
\hline C. albicans 1 & Blood & KJ740179 & FLC, ITRA, VRZ & 64 \\
\hline C. albicans 2 & Blood & KJ740175 & FLC, VRZ & 64 \\
\hline C. albicans $3 * / * *$ & Blood & AB861478 & FLC, ITRA & 64 \\
\hline C. albicans 4 & Blood & KJ740176 & FLC, ITRA, VRZ & 64 \\
\hline C. albicans 5 & Blood & KJ740174 & FLC, ITRA, VRZ & 64 \\
\hline C. albicans 6 & Blood & AB861479 & FLC, VRZ & 128 \\
\hline C.parapsilosis 1 & Blood & KJ740188 & FLC, ITRA & 32 \\
\hline C. parapsilosis 2 & Blood & AB861485 & FLC, ITRA & 64 \\
\hline C.parapsilosis 3 & Blood & KJ740191 & FLC, ITRA & 32 \\
\hline C. parapsilosis $4 * *$ & Blood & KJ740186 & FLC, ITRA & 32 \\
\hline C. parapsilosis 5 & Blood & AB861488 & FLC, ITRA & 128 \\
\hline C. parapsilosis 6 & Blood & AB861486 & FLC, ITRA, VRZ & 80,6 \\
\hline C. parapsilosis 7 & Blood & AB861487 & FLC, VRZ & 101,6 \\
\hline C.tropicalis $1 * *$ & Blood & AB861490 & FLC, ITRA, VRZ & 64 \\
\hline C.tropicalis 2 & Blood & KJ740181 & FLC, ITRA, VRZ & 64 \\
\hline C.tropicalis 3 & Urine & AB861491 & FLC & 64 \\
\hline C.tropicalis 4 & Blood & KJ740185 & FLC, ITRA, VRZ & 64 \\
\hline C.tropicalis 5 & Blood & AB861493 & FLC, VRZ & 50,8 \\
\hline C.tropicalis 6 & Blood & KF616840 & FLC, ITRA & 64 \\
\hline C. glabrata 1 & Blood & AB861484 & FLC, ITRA, VRZ & 64 \\
\hline C.parapsilosis ATCC 22019 & - & - & - & 32 \\
\hline C.krusei ATCC 6258 & - & - & - & 64 \\
\hline
\end{tabular}

${ }^{a}$ Yeasts isolated from biological samples. FLC: Fluconazole; ITC: Itraconazole; VRZ: Voriconazole

${ }^{\mathrm{b}} \mathrm{MIC}_{50}$ value was defined as the lowest concentration that produced a $50 \%$ reduction in the growth of fungal cells after $24 \mathrm{~h}$ incubation.

*Strains used to investigate the mechanism of action of palmatine. ** Strains used for the biofilm assay. 
An analysis of DNA damage was performed using comet assay, alkaline version, which can detect single and double DNA strand breaks. Double strand lesions are difficult to repair, and may result in cell death or in deleterious mutations. Furthermore, simple breaks can be converted to double breaks during the replication process (Da Silva et al., 2014). Palmatine induced an intense DNA damage in $C$. albicans cells. Some studies demonstrate that palmatine binds strongly to DNA (Bhadra, Maiti, Kumar, 2007; Mi et al., 2015). In order to verify whether palmatine causes oxidative damage to DNA, the comet assay, alkaline version, was also performed in the presence of the FPG enzyme. This enzyme improves the specificity of the test by identifying oxidized purine bases (adenine and guanine).

In this study, there was no difference between the comet assay in the absence and the presence of the FPG enzyme, showing that palmatine does not cause oxidation of purine bases. Similar data were obtained by Da Silva et al., (2016) who showed that berberine induces severe damage to DNA, but that oxidative damage does not occur since results are similar in the presence and absence of the FPG enzyme.

During apoptosis, phosphatidylserine (PS), an inner membrane phospholipid, is externalized to the surface of the cell membrane, signaling that the cell is phagocytized by macrophages. Annexin $\mathrm{V}$ is a marker that has a high affinity for PS and binds to the PS externalized in cell undergoing apoptosis (Hwang et al., 2012; Choi and Lee, 2015). Palmatine, at the three concentrations, produced an increase in phosphatidylserine externalization in $C$. albicans cells, indicating that these cells are in an early apoptosis process. Similar data were also verified by (Da Silva et al., 2016) upon performing the same test using berberine in $C$. albicans.
Many studies show that palmatine binds strongly to DNA and attempt to elucidate how this process occurs (Bhadra, Maiti, Kumar, 2007; Mi et al., 2015; Dumont and Monari, 2015). According to the results of this study, it can be proposed that palmatine acts at the DNA level causing secondary changes that, by secondary processes, cause mitochondrial depolarization, leading to fungal cell death by apoptosis, as demonstrated by the externalization of phosphatidylserine test.

Palmatine showed an activity in Candida spp. resistant to azoles in planktonic cells and also in the form of biofilms. When microorganisms are organized in the form of biofilms, they have a rather higher resistance to antifungal agents when compared to their planktonic form (Bonhomme and d'Enfert, 2013). Two methodologies were used to verify the antifungal action in biofilms. The first considers the biofilm already formed; it is assessed whether the drug is able to eradicate an existing biofilm. The other methodology is inhibition of the formation of biofilm, i.e., the drug must act preventing the formation of biofilm generally by disrupting cell adhesion processes (Rane et al., 2014; Sun, Liao, Wang, 2015).

The initial stage of biofilm formation is adhesion to a surface influenced by abiotic factors such as hydrophobicity and biotic factors such as increased production of adhesin and other surface proteins. Therefore, the inhibition of adhesion of Candida species is a promising target to halt the early stages of biofilm formation. The results of this study show that palmatine acts both in formed biofilms and biofilms in formation in the three tested species of Candida resistant to azoles. This is a key characteristic for a drug with a suitable antifungal action, since an ideal antifungal drug should have both the ability to kill the biofilm and to inhibit its formation (Theberge et al., 2013). 
Valentin et al., (2012) shows that azoles, including voriconazole, have no activity against pre-formed Candida spp. biofilm. This resistance may be explained by the high expression of efflux pumps at the early stages of biofilm formation and low levels of ergosterol at the intermediate and late stages. However, fluconazole and caspofungin may prevent the formation of biofilm when the surface over which it is formed is pretreated with such drugs or when the biofilm is formed in the presence of these drugs. In the 24-hour formed biofilm, palmatine could decrease by $50 \%$ the viability of the biofilm in $C$. tropicalis strains resistant to azole at the concentration 10x MIC. The same test performed by (Da Silva et al., 2016) showed that berberine was able to produce the same inhibition rate at the concentration $4 \mathrm{x}$ MIC for a strain of $C$. tropicalis resistant to fluconazole. These results are very promising since biofilms are difficult to eradicate, representing continuous infection outbreaks (Valentin et al., 2012; Yu et al., 2008).

An evaluation of viability cell in $C$. albicans resistant to azoles after 3, 6, 12 and $24 \mathrm{~h}$ of treatment with palmatine at the MIC, $2 \mathrm{x}$ MIC and 4x MIC. * $\mathrm{P}<0.05$ compared to the results for the control, determined by ANOVA followed by the Newman-Keuls test. An evaluation of ROS formation in $C$. albicans resistant to azoles after 3, 6, 12 and $24 \mathrm{~h}$ of treatment with palmatine at the MIC, $2 \mathrm{x}$ MIC and 4x MIC. * $\mathrm{P}<0.05$ compared to the results for the control, determined by ANOVA followed by the Newman-Keuls test.

Effects of different treatments on the mitochondrial transmembrane potential in strain of $C$. albicans resistant to azoles exposed for 3, 6, 12 and $24 \mathrm{~h}$ to palmatine (MIC, 2x MIC and 4x MIC) and Ampho (4 $\mu \mathrm{g} / \mathrm{mL}) .{ }^{*} \mathrm{P}<0.05$ compared to the results for the control, determined by ANOVA followed by the Newman-Keuls test.
Effect of palmatine at the MIC, 2x MIC and 4x MIC on phosphatidylserine externalization in $C$. albicans resistant to azoles for $3,6,12$ and 24 h of treatment. $* \mathrm{P}<0.05$ compared to the results for the control, determined by ANOVA followed by the Newman-Keuls test.

Effects of different treatments on the DNA damage index and on the distribution of oxidative DNA damage in $C$. albicans resistant to azoles determined using of the comet assay. $C$. albicans was exposed to RPMI (control), palmatine (MIC, 2x MIC and 4x MIC) and amphotericin B $(4 \mu \mathrm{g} / \mathrm{ml})$. * $\mathrm{P}<$ 0.05 compared to the results for the control, determined by ANOVA followed by the Newman-Keuls test.

Effect of different concentrations of palmatine on the metabolic activity of biofilms formed of $C$. albicans resistant to azoles analyzed by the MTT reduction assay. * $\mathrm{P}<0.05$ compared to the results for the control, determined by ANOVA followed by the Tukey test.

Effect of different concentrations of palmatine on inhibition of biofilm formation in $C$. albicans resistant to azoles analyzed by the MTT reduction assay. * $\mathrm{P}<0.05$ compared to the results for the control, determined by ANOVA followed by the Tukey test.

Palmatine has an antifungal activity against Candida strains resistant to azoles. Its mechanism of action involves mitochondrial depolarization and DNA damage, leading to cell death by apoptosis. Palmatine was able to reduce the viability of the formed biofilm and to inhibit the formation of biofilms in Candida spp. resistant to azoles.

Because there is no cytotoxicity regarding mammalian cells, palmatine can be considered a potential candidate for a new drug with an anti-candida action. 


\section{Acknowledgments}

This work was supported by grants and fellowships from CNPq, CAPES/ Brazil, and FUNCAP/ Ceará.

\section{References}

Ali, H., Dixit, S., 2013. Extraction optimization of Tinospora cordifolia and assessment of the anticancer activity of its alkaloid palmatine. Sci World J, 2013;2013. doi:10.1155/2013/376216.

Bhadra, K., Maiti, M., Kumar, G. S., 2007. Molecular recognition of DNA by small molecules: AT base pair specific intercalative binding of cytotoxic plant alkaloid palmatine. Biochim Biophys Acta 1770, 1071-1080.

Bonhomme, J., d'Enfert, C., 2013. Candida albicans biofilms: Building a heterogeneous, drug-tolerant environment. Curr Opin Microbiol 16, 398-403.

Choi, H., Lee, D. G., 2015. Lycopene induces apoptosis in Candida albicans through reactive oxygen species production and mitochondrial dysfunction. Biochimie 115, 108-15.

Clinical and Laboratory Standards Institute (CLSI), 2012. Reference Method for Broth Dilution Antifungal Susceptibility Testing of Yeasts; Fourth Informational Supplement. CLSI document M27- S4. Clinical and Laboratory Standards Institute, Wayne, PA.

Da Silva, A. R., De Andrade Neto, J. B., Da Silva, C. R., Campos, R.S., Costa Silva, R. A., Freitas, D. D., Nascimento, F. B. S. A., Andrade, L. N., Sampaio, L. S., Grangeiro, T. B., Magalhães, H. I., Cavalcanti, B. C., Moraes, M. O., Nobre Júnior, H. V., 2016. Berberine Antifungal Activity in Fluconazole-resistant Pathogenic Yeasts: Action Mechanism Evaluated by Flow Cytometry and Biofilm Growth Inhibition in Candida spp. Antimicrob Agents Chemother 60, 3551-7.

Da Silva, C. R., De Andrade Neto, J. B., De Sousa Campos, R., Figueiredo, N. S., Sampaio, L. S., Magalhães, H. I. F., Cavalcanti B. C., Gaspar, D. M., de Andrade, G. M., Lima, I. S., de Barros Viana, G. S., de Moraes, M. O.,
Lobo, M. D., Grangeiro, T. B., Nobre Júnior, H. V., 2014. Synergistic effect of the flavonoid catechin, quercetin, or epigallocatechin gallate with fluconazole induces apoptosis in Candida tropicalis resistant to fluconazole. Antimicrob Agents Chemother 58, 1468-78.

Dumont, É., Monari, A., 2015. Interaction of palmatine with DNA: An environmentally controlled phototherapy drug. J Phys Chem B 119, 410-9.

Galluzzi, L., Morselli, E., Kepp, O., Vitale, I., Rigoni, A., Vacchelli, E., Michaud, M., Zischka, H., Castedo, M., Kroemer, G., 2010. Mitochondrial gateways to cancer. Mol Aspects Med 31, 1-20.

Guo, Q., Sun, S., Yu, J., Li, Y., Cao, L., 2008. Synergistic activity of azoles with amiodarone against clinically resistant Candida albicans tested by chequerboard and time-kill methods. J Med Microbiol 57, 45762.

Hwang, J. H., Choi, H., Kim, A. R., Yun, J. W., Yu, R., Woo, E. R., Lee, D. G.,2014. Hibicuslide C-induced cell death in Candida albicans involves apoptosis mechanism. J Appl Microbiol 117, 1400-11.

Hwang, J. H., Hwang, I. S., Liu, Q. H., Woo, E. R., Lee, D. G., 2012. (+)-Medioresinol leads to intracellular ROS accumulation and mitochondria-mediated apoptotic cell death in Candida albicans. Biochimie 94, 1784-93.

Kazak, E., Akın, H., Ener, B., Sığırli, D., Özkan, O., Gürcüoğlu, E., Yılmaz, E., Çelebi, S., Akçağlar, S., Akalın, H., 2014. An investigation of Candida species isolated from blood cultures during 17 years in a university hospital. Mycoses 57, 623-9.

Kumar, D., Kumar, A., Singh, S., Tilak, R., 2015. Candidemia-induced pediatric sepsis and its association with free radicals, nitric oxide, and cytokine level in host. J Crit Care 30, 296-303.

Mi, R., Tu, B., Bai, X. T., Chen, J., Ouyang, Y., $\mathrm{Hu}$, Y. J., 2015. Binding properties of palmatine to DNA: Spectroscopic and molecular modeling investigations. Luminescence 30, 1344-51.

Park, K., Kang, K., Kim, J., Adams, D. J., Johng, T., 1999. The C. Differential inhibitory effects of protoberberines on sterol and chitin 
43, 667-74.

Pires, R. H., Da Silva, J. F., Martins, C. H. G., Almeida, A. M. F., Soares, C. P., MendesGiannini, M. J. S., 2013. Effectiveness of disinfectants used in hemodialysis against both Candida orthopsilosis and C. parapsilosis sensu stricto biofilms. Antimicrob Agents Chemother 57, 2417-21.

Pustovidko, A. V., Rokitskaya, T. I., Severina, I. I., Simonyan, R. A., Trendeleva, T.A., Lyamzaev, K. G., Antonenko, Y. N., Rogov, A. G., Zvyagilskaya, R. A., Skulachev, V. P., Chernyak, B. V., 2013. Derivatives of the cationic plant alkaloids berberine and palmatine amplify protonophorous activity of fatty acids in model membranes and mitochondria. Mitochondrion 13, 520-5.

Qi, H., Xiao, Z., Ma, J., Duan, S., Wang, Y., 2013. Comparative Study of Antimicrobial Effects of Three Chinese Medicinal Herbs Containing Protoberberine Alkaloids. Latin American Journal of Pharmacy 32, 335- 9.

Rane, H. S., Bernardo, S. M., Howell, A. B., Lee, S. A.,2014. Cranberry-derived proanthocyanidins prevent formation of Candida albicans biofilms in artificial urine through biofilm- and adherence-specific mechanisms. J Antimicrob Chemother 69, 428-36.

Storti, L. R., Pasquale, G., Scomparim, R., Galastri, A. L., Alterthum, F., Gambale, W., Rodrigues Paula, C., 2012. Candida spp. isolated from inpatients, the environment, and health practitioners in the pediatric unit at the Universitary Hospital of the Jundiaí Medical College, state of São Paulo, Brazil. Rev Soc
Bras Med Trop 45, 225-31.

Sun, L., Liao, K., Wang, D., 2015. Effects of magnolol and honokiol on adhesion, yeasthyphal transition, and formation of biofilm by candida albicans. PLoS One 10, e0117695.

Tabbene, O., Azaiez, S., Di Grazia, A., Karkouch, I., Ben Slimene, I., Elkahoui, S., Alfeddy, M. N., Casciaro, B., Luca, V., Limam, F., Mangoni, M. L., 2016.Bacillomycin D and its combination with amphotericin B: Promising antifungal compounds with powerful antibiofilm activity and wound-healing potency. J Appl Microbiol 120, 289-300.

Theberge, S., Semlali, A., Alamri, A., Leung, K. P., Rouabhia, M. C., 2013. C. albicans growth, transition, biofilm formation, and gene expression modulation by antimicrobial decapeptide KSL-W. BMC Microbiol 13, 246. doi:10.1186/1471-2180-13-246.

Valentin, A., Canton, E., Peman, J., Martinez, J. P., 2012. Voriconazole inhibits biofilm formation in different species of the genus Candida. J Antimicrob Chemother 67, 241823.

Yapar, N., 2014. Epidemiology and risk factors for invasive candidiasis. Ther Clin Risk Manag 10, 95-105.

Yu, L. H., Wei, X., Ma, M., Chen, X. J., Xu, S. B., 2012. Possible inhibitory molecular mechanism of farnesol on the development of fluconazole resistance in Candida albicans biofilm. Antimicrob Agents Chemother 56, 770-5.

Zavrel, M., White, T. C., 2015. Medically important fungi respond to azole drugs: an update. Future Microbiol 10, 1355-73.

\section{How to cite this article:}

Rosana de Sousa Campos, Cecília Rocha da Silva, João Batista de Andrade Neto, Letícia Serpa Sampaio, Francisca Bruna Stefany Aires do Nascimento, Manoel O. de Moraes, Bruno Coêlho Cavalcanti, Hemerson Iury Ferreira Magalhães, Akenaton Onassis Cardoso Viana Gomes, Marina Duarte Pinto Lobo and Hélio Vitoriano Nobre Júnior. 2018. Antifungal Activity of Palmatine against Strains of Candida spp. Resistant to Azoles in Planktonic Cells and Biofilm. Int.J.Curr.Microbiol.App.Sci. 7(02): 3657-3669. doi: https://doi.org/10.20546/ijcmas.2018.702.435 